THE UNNATURAL HISTORY OF AORTIC STENOSIS.

85 William Berman, Jr., Steven M. Yabek,

Raymond R. Fripp, Terrence Dillon, and Rochelle Burstein. UNM School of Med. , UNM Hosp., Ped. Dept., Albuquerque, New Mexico. we report on the clinical course and serial hemodynamic studies of three patients with severe valuar aortic stenosis diagnosed in the neonatal period. None of the subjects was symptomatic in the first year of life. In each case, a conservative inftial management approach was adopted. Between the time of initial study (mean age 1.8 months) and the follow up at 12-27 months of age (mean 14.3 months), mean left ventricular systolic pressure fell from 151 to $135 \mathrm{mmHg}$, the mean peak systolic pressure gradient the mean calculated aortic valve area index increased from 0.20 to $0.39 \mathrm{~cm}^{2} /$ meter $^{2}$. One of the patients was operated on for symptoms which appeared at 14 months of age. The patient followed longest is now 5 years old, is growing well, has a normal electrocardiogram and an echo-predicted left ventricular systolic pressure of $128 \mathrm{mmHg}$. This experience suggests that not all asymptomatic neonates with severe valvar aortic stenosis require surgical intervention early in life. In some, the aortic valve orifice may increase in size with somatic
growth and obviate the need for surgery in early growth and

VENTRICULAR ARRHYTHMOGENESIS AND SUDDEN DEATH: Ilistologic Correlates in Two Young Females: S. Bharaţi, 86 Brookdale Hospital Medical Center and Deborah Heart and Lung Center, Browns Mills, New Jersey

Two female Pts. ages 5 and 14, with history of ventricular dysrrhythmia (VD) died suddenly. Pt I, had post-natal chaotic AV block and a prolonged $Q T$ interval. The infant required transvenous ventricular pacing which controlled the arrhythmia by overdrive suppression. A permanent eptcardial unipolar VVI pacemaker was implanted at one week of age. The $\mathrm{Pt}$ had a normal hemodynamic study and complete RBB block pattern with left axis deviation with pacing. Febrile seizures occurred at age 5. Holter studies demonstrated normal pacemaker function and capture and no ventricular ectopy. Two weeks prior to her sudden death, a short self terminated run of VT was noted. Autopsy revealed an enlarged heart. Conduction system (CS) revealed chronic, patchy infiltration of cells in the myocardium and neuritis, with fibrosis of the bundle and the beginning of the bundle branches. Pt 2, had a 6 year history of paroxysmal VT, normal EP studies, was asymptomatic and was free of VD on proprananol. A brother with an identical condition had documented clinical and EP evidence of catechol induced ventricular premature beats and VT. Autopsy revealed cardiomegaly, a left sided His bundle, and markedly dilated veins pressed on the AV node. A conal muscle from the right side pressed on the bifurcating bundle, and the RBB was intramyocardial.

In summary, arrhythmogenicity could have been triggered by changes in the $C S$ resulting in sudden death in both pts.

DOES CENTRAL FAT DEPOSITION (CF)

87 DETERMINE SBP:MCV HEART STUDY. JOANn Bodurtha, Richard Schieken, Michael Mosteller,, Lindon Eaves, Walter Nance. Medical College of Va., Depts. of

Pediatrics and Genetics. Richmond VA.

We studied 20011 year-old twin pairs and their parents and asked: 1) Is there a relationship of $\mathrm{cF}$ with systolic blood pressure (SBP)? 2) Are there sex differences and do they relate to sexual maturity? 3) Do measures of CF relate to SBP in adults? significant relationships of SBP to anthropometric measures are tabulated $(p<.05)$

$\begin{array}{lcccc} & \text { All twins } & \text { DZ twins } & \text { Girls } & \text { Boys } \\ \text { Height } & 0.03 & 0.25 & 0.32 & 0.28 \\ \text { Weight } & 0.36 & 0.36 & 0.23 & 0.34 \\ \text { Suprailiac(SI } & 0.27 & 0.15 & 0.31 & 0.22 \\ \text { CF(SI/Triceps) } & 0.24 & 0.19 & 0.34 & \mathrm{NS} \\ \text { S were more sexually mature than boys }\end{array}$
Girls were more sexually mature than boys (Tanner $=$ 2.5 vs $2.0 \mathrm{p}<.001$ ). In mothers but not fathers SBP correlated both with weight $(r=0.26)$ and SI $(r=0.29)$. In a model using height, weight, and $C F$ to explain $r^{2}=17$ variance of SBP in girls, only CF was significant $r^{2}=17 \%$ We conclude: 1) CF explains a significant proportion of the variance of SBP in girls, 2) These 3) the relationship of CF to SBP is seen in mothers 3) the relationship of CF to SBP is seen in mothers sexual hormones may mediate this process.
EXPERIMENTAL USE OF A NEW ATRIALLY PASSED, SUTURELESS, VENTRICULAR APEX TO AORTA CONDUIT.

88 Mark M. Boucek, Richard Chang and Edwin C. McGough. TSpon. by Michael A. Simmons). University of Utah and Primary Children's Hospital Salt Lake City, Utah

Ventricular outflow obstruction in the infant remains a surgical challenge with high operative mortality despite a variety of approaches. An apical to aortic conduit would be a direct approach but usually required cardiopulmonary bypass and removal or fixation of perhaps a critical amount of apical myocardium.

Therefore, we developed a two component apical prosthesis consisting of a grommet, fixed internally by a flange, that can be placed via the atrium wi thout bypass and an external female adaprequire removal of myocardial tissue or sutures. The TAVAD concept was acutely tested in 8 anesthesized dogs (mean wt. $=15 \mathrm{~kg}$ ). Initially the TAVAD device was capped and acute stability in the myocardium was demonstrated in 5 dogs. Subsequently, in 3 dogs, the TAVAD method was used to achieve communication with a valved conduit to the thoracic aorta. Acute grommet stability in the myocardium was evident even with the conduit attached and ventricular pressures up to $250 \mathrm{mmHg}$. The ability to carry cardiac output was demonstrated by ascending aortic occlusion. Chronic implantation off bypass in 3 lambs (mean wt. $=8.5 \mathrm{~kg}$ ) has shown continued myocardial fixation and conduit function. Angiography demonstrated unobstructed apical to aortic flow and normal ventricular wall motion. Since the lamb myocardium is similar in thickness to the human infant, we conclude that the TAVAD device and method may be useful in relieving ventricular outflow obstuc-

DOXORUBICINOL, THE METABOLITE OF DOXORUBUCIN, IS MORE CARDIOTOXIC THAN DOXORUBICIN. Robert J. Boucek, Jr.,

89 Edna M. Kunkel, Thomas P. Graham, Jr.. Dean Brenner, Richard D. Olson. Vanderbilt University School of Department of Pediatrics, Nashville; Roswell Park Memorial Institute, Buffalo; VA Medical Center, Boise.

The clinical utility of the cancer chemotherapeutic agent doxorubicin (DOX) is limited by its cardiotoxicity. Doxorubicinol (DOxol), the major biometabolite of Dox, preferentially accumulates in heart during chronic Dox administration. We now find lates in heart during chronic Dox administration. We now find that DoXol is cardioactive, increasing resting stress in isometriValues in the table were measured after the addition of $50 \mathrm{ug} / \mathrm{ml}$ of DOXol or DOX and expressed as the percent $(\bar{x} \pm \mathrm{SE})$ of pretreatment control values.

Resting Stress $(n=5)$ $\mathrm{Na} / \mathrm{Ca}$ exchange (SL) (n=4)

$\begin{array}{cc}\text { DOXol } & \text { DOX } \\ 42+488 & 10 \frac{9+58}{78+10 z}\end{array}$
An increase in resting stress indicates failure of myofibrils to relax and may be related to intracellular calcium ([Ca],). The table also shows that the greater potency of Doxol, relative to DOX, to increase resting stress correlates with Doxol's greater potency to inhibit, in-vitro, two major determinants of resting [Ca] isotopic $\mathrm{Na} / \mathrm{Ca}$ exchange rate of membrane vesicles enriched in sarcolemma (SL) and Ca pump activity of membrane vesicles enriched in sarcoplasmic reticulum (SR)

Thus we speculate that the abnormalities in myocardial relaxation noted in the chronic cardiotoxicity of Dox may be related to the effects of DOXol on membrane regulation of $[\mathrm{Ca}]_{i}$.

\section{CARDIAC MUSCARINIC RECEPTORS IN CONOTRUNCAL}

90 ABHORMALITIES. James L. Christiansen, Wesley Covitz. College of Georgia, Department of Pediatrics, Augusta, Georgia. (Sponsored by William B. Strong) Cranial neural crest contributes to aorticolpulmonary septation as well as to the parasympathetic innervation of the heart. To determine whether parasympathetic innervation of
the heart is altered in a human conotruncal abnormality (Tetralothe heart is altered in a human conotruncal abnormality (Tetralo muscarinic receptors were studied in atrial appendage tissue obtained during corrective surgery. Tissue from children with TOF was compared with tissue from children with a defect not involving the aorticopulmonary septum (secundum atrial septal defect; ASD). Muscarinic receptor density (Bmax) and antagonist affinity $\left(K_{D}\right)$ were determined using [ $\left.3 \mathrm{H}\right] 3$-quinuclidinylbenzilate $\left(\left[{ }^{3} \mathrm{H}\right] \mathrm{QNB}\right)$. Agonist binding properties were determined in carbamylcholine (Carb)/[ $\left.{ }^{3} \mathrm{H}\right]$ QNB competition studies. Carb binding was resolved into high and low affinity components characterized by. $K_{H}$ and $K_{L}$, and by $R_{H}$, the fraction of receptors displaying high affinity binding. No differences were seen in TOF and ASD atria (Means \pm S.D. : : $\quad\left[{ }^{3} \mathrm{H}\right]$ QNB

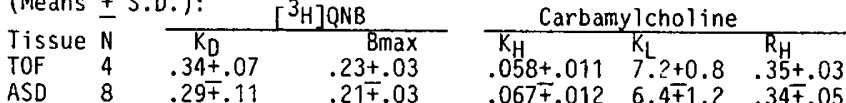

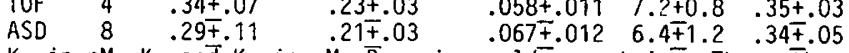
$K_{D}$ in $n M, K_{H}$ and $K_{L}$ in $u M, \bar{B} \max$ in $\mathrm{pmol} / \overline{m g}$ protein. Thus, there is an apparent dissociation of the consequences of depletion of mesenchymal vs neural crest in TOF. Alternatively, the neural crest insult which causes TOF may not be of sufficient magnitude to affect cardiac muscarinic receptors. 